DOI: http://dx.doi.org/10.1590/S1414-40772016000300005

\title{
PROUNI - pontos controversos sob a análise de alunos bolsistas
}

\author{
Tereza Lúcia Lima Fontele \\ Vicente Lima Crisóstomo
}

Resumo: Este trabalho analisa o Programa Universidade para Todos- PROUNI, criado como uma política afirmativa de democratização do acesso à educação superior. Materializado numa transação entre instituições privadas de educação superior e o governo federal, mediante incentivos fiscais, o PROUNI tem despertado bastantes polêmicas. Considerando que a efetividade de um programa dessa magnitude só pode analisada em médio e longo prazo, este trabalho soma-se ao debate sobre essa política pública, levado a efeito em distintos fóruns. $\mathrm{O}$ artigo tem como objetivo a realização de uma análise do programa a partir da opinião dos seus beneficiários, considerando que pouco há sido feito nessa direção. A partir do cotejamento de opiniões de bolsistas do PROUNI, pode-se alcançar a apreciação dessa política pública sob a óptica desses estudantes, procedimento considerado relevante, sobretudo por ter alargado os prismas da análise. Os resultados alcançados sinalizam que, de fato, o PROUNI atende às demandas de determinado segmento da população por inclusão no ensino superior. No entanto, os beneficiários consideram que há necessidade de ajustes no programa e que a formação acadêmica que ora recebem foi definida mais por perspectivas do mercado de trabalho e por conveniências das instituições que pelo critério da aptidão. A atividade laboral foi apontada como justificativa ao baixo desempenho acadêmico dos bolsistas, tendo sido encontrados na fala dos beneficiários indícios da existência de discriminação.

Palavras-chave: Políticas educacionais. Educação superior. Programa Universidade para Todos - PROUNI. Democratização do acesso ao ensino superior.

\section{PROUNI - controversial topics under the view of scholarship students}

Abstract: This paper analyzes the University for All Program - PROUNI, created as an affirmative policy of higher education access democratization. Materialized in a transaction between private institutions of higher education and the Federal Government, through tax incentives, PROUNI has been quite controversial. Whereas the effectiveness of a program of such magnitude can only be examined in the medium and long term, this study adds to the debate about this policy. The article aims to conduct an analysis of the program from the view of its beneficiaries, considering that little has been done in this direction. By collating beneficiaries' opinions it is possible to attain the program assessment from this relevant perspective. The results indicate that, in fact, PROUNI meets the demands of a particular segment of the population for inclusion in higher education. However, beneficiaries consider that the program needs adjustments, and that their academic carrier has been defined more by prospects of labor market and by institutions conveniences than for personal fitness criterion. Labor activity has been appointed as the reason to the low academic performance, and there is symptom of the existence of discrimination.

Key words: Educational policies. Higher education. Program University for all - PROUNI. Democratizing access. 


\section{Introdução}

No Brasil, habitualmente, a avaliação das políticas educacionais norteia-se por parâmetros expressos em números, razão por que, muitas vezes, o processo chega a resultados descolados da contextualização e da apreciação dos beneficiários diretos dessas ações. No momento em que o segmento da educação superior adotou oficialmente a avaliação como forma de fazer toda a comunidade (interna e externa) assumir sua posição de corresponsável pelas ações governamentais desenvolvidas no setor, ampliou-se o espaço de discussões sobre as políticas públicas ora em prática no campo da educação formal, de modo que hoje os processos avaliativos das políticas públicas educacionais já começam a extrapolar a mera atualização numérica de indicadores preestabelecidos, para, a partir do envolvimento dos destinatários dessas ações e da análise dos critérios subjacentes a sua base de concepção, alcançar seus aspectos intangíveis.

O Programa Universidade para Todos - PROUNI, criado pela Lei $n^{\circ} 11.096$, de 13 de janeiro de 2005 (BRASIL, 2005), como política afirmativa de democratização do acesso ao ensino superior, tem sido objeto de algumas análises, boa parte delas eivadas de ranços ideológicos, reconhecidamente prejudiciais ao entendimento global do programa, porquanto, além de estreitarem o campo de avaliação, redundam em posições radicais e estéreis. Amoldados à busca de dados materialmente homologáveis, esses trabalhos praticamente têm-se restringido ao cotejamento entre os indicadores do dispêndio que o programa implica e o retorno social dele esperado, razão por que a voz dos beneficiários do programa costuma não ser levada em consideração. Trata-se, pois, de uma contradição, sobretudo se se considerar o crescente clamor social por melhor qualidade e mais amplitude de serviços públicos, bem como a necessidade imperiosa de tornar compatíveis as demandas sociais com as boas práticas de mercado, que têm o cliente como elemento relevante no processo de prestação de serviço. Movimentos sociais recentes têm demonstrado que os beneficiários de políticas públicas estão querendo ter um papel mais ativo nos processos de concepção e elaboração destas.

Especificamente sobre o PROUNI, a literatura tem destacado a necessidade de avaliação do programa e a dificuldade de obtenção de dados que viabilizem esse estudo apreciativo (SEGENREICH, 2009; SILVA; VELOSO, 2013). Com o objetivo de tentar elucidar, ainda que parcialmente, os questionamentos suscitados pelas contraditórias análises do Programa Universidade para Todos - PROUNI, tido por uns como uma política pública capaz de resgatar uma dívida historicamente contraída com os segmentos mais pobres da sociedade 
no campo da educação superior e, por outros, como uma capitulação à lógica capitalista, este artigo apresenta resultados de uma pesquisa com bolsistas do programa, pretendendo-se, pois, um contributo às discussões sobre essa política de democratização do acesso à educação superior, dessa vez, agregando a visão de seus beneficiários, algo já apontado como relevante pela literatura (AMARAL; OLIVEIRA, 2011; SARAIVA; NUNES, 2011).

A pesquisa foi feita com uma amostra de 50 (cinquenta) beneficiários do PROUNI, com o propósito deliberado de tirar deles “opiniões, crenças, sentimentos, interesses, expectativas, situações e vivências" relativos ao programa (DALBERIO; DALBERIO, 2009). Com esse propósito, a grupo pesquisado, apresentaram-se questionamentos acerca de pontos como a razão da escolha do curso superior em andamento, as dificuldades enfrentadas por esses estudantes durante o percurso formativo e a ocorrência de eventuais casos de discriminação no ambiente universitário. Por fim, solicitou-se aos estudantes uma apreciação pessoal do PROUNI, como uma forma adicional e reconhecidamente importante de avaliá-lo. Afinal, é sobre seus beneficiários que os efeitos dessa política pública, positivos ou negativos que sejam, recairão diretamente.

Sinteticamente, a análise dos pontos postos em questão revelou que boa parte dos beneficiários frequentam cursos definidos mais pelas conveniências das IES e menos pelos critérios da aptidão e da preferência pessoal. Relativamente às dificuldades enfrentadas no percurso formativo, 56\% dos entrevistados afirmaram estar enfrentando-as. Quanto à incidência de discriminação aos beneficiários do PROUNI entrevistados, um percentual de 30\% deles declarou-se discriminado por professores, funcionários das IES, e ainda por colegas pagantes. O PROUNI foi bem avaliado pelos estudantes, embora tenha sido possível detectar na fala deles, além de um traço de frustração por não terem conseguido uma vaga numa IES pública, indícios de que o programa carece de ajustes. Também integra este artigo uma análise da argumentação dos pesquisados, o que implicou ultrapassar a materialidade linguística para alcançar as relações de sentido a elas subjacentes.

Vemos este trabalho como uma contribuição ao debate sobre o PROUNI, sobretudo por apresentar a visão dos beneficiários, como feito por Saraiva e Nunes (2011) em outra região do país. A opinião dos beneficiários agrega importantes elementos aos argumentos do governo, que vê no programa apenas resultados meritórios, posição não coincidente com a visão de muitos avaliadores de políticas educacionais, principalmente no ponto que trata do uso de recursos públicos para financiamento da iniciativa privada na área educacional. 
Este trabalho está estruturado em cinco seções, incluindo a introdução e a conclusão. A seção 2 aborda políticas governamentais direcionadas à democratização do acesso ao ensino superior, com foco no Programa Universidade para Todos - PROUNI; na seção seguinte, tem-se a apresentação do caminho metodológico adotado. A análise da argumentação contida nas respostas dos pesquisados às perguntas formuladas é apresentada na seção 4, juntamente com as ilações alcançadas.

\section{Políticas afirmativas de acesso ao ensino superior}

Apesar das limitações materiais ou políticas, a busca da universalização do ensino tem estado sempre presente no discurso de seguidos governos de nosso país. Nesse contexto, a ampliação da oferta de vagas no ensino superior aparece com especial destaque, quase sempre sob a alegação de ser inadiável a formação de profissionais mais qualificadas em diversas áreas, como forma de acelerar o compasso de desenvolvimento do Brasil (CATANI; HEY, 2007). Ainda que a premência da formação dessa mão de obra seja irrefutável, tanto no Brasil como em vários outros países, a problemática do financiamento da educação teima em subsistir, de modo que o debate sobre a avaliação de instituições de ensino superior e a prática de destinar recursos públicos para financiar o ensino superior na rede privada continua deveras oportuno (WORLD BANK, 1994).

A história do ensino superior no Brasil revela ter estado a tarefa de gerir esse nível de ensino predominantemente nas mãos do Estado e que não têm sido raras as situações de escassez de recursos públicos para investimento no setor. Recentemente, e com o beneplácito do governo brasileiro, a iniciativa privada aumentou consideravelmente a participação no segmento da educação superior, fato coincidente com a redefinição do papel do Estado, em cujo arcabouço incluiu-se a autonomia das instituições federais de ensino superior (IFES). Essas estratégias, adotadas em distintos países, têm-se bifurcado nas direções de ampliar a oferta de vagas no ensino superior e de melhorar a qualidade desse nível educacional. No Brasil, o debate sobre a democratização do acesso ao ensino superior, presente tanto na pauta de governos como na de grupos de pressão, tem ocorrido em paralelo com outras questões, por exemplo, a avaliação de instituições de ensino superior (FÁVERO, 2006; ZANDAVALLI, 2009). Fruto dessas discussões, a facilitação do acesso ao ensino superior no formato de ações afirmativas vem ganhando corpo, cabendo aqui destacar a ampliação da rede pública de ensino superior em distintos momentos, o estímulo à entrada da iniciativa privada no setor e o financiamento público de 
estudos universitários, primeiro pela via do Crédito Educativo, programa de 1975, e, mais recentemente, por meio do Fundo de Financiamento Estudantil (FIES), institucionalizado pela Lei 8.436/1992, alterada pelas Leis 9.288/1996, 10.260/2001 e 11.941/2009 (BRASIL, 1992, 1996, 2001, 2009).

\subsection{Programa Universidade para Todos (PROUNI)}

O Programa Universidade para Todos (PROUNI), criado pela Lei n ${ }^{\circ} 11.096$, de 13 de janeiro de 2005 (BRASIL, 2005), concede bolsas de estudos em instituições privadas de ensino superior para a realização de cursos de graduação e sequenciais de formação específica, o que se dá sob a forma de incentivos fiscais do governo federal. Atualmente, o programa configura-se como importante política afirmativa de discriminação positiva, com a característica de ser um financiamento sem ônus direto para o estudante.

O financiamento do PROUNI é feito pela via do incentivo fiscal, nos termos do Art. $8^{\circ}$ da Lei no 11.096/2005 (BRASIL, 2005). A renúncia fiscal, com finalidade social, já é prática verificada no Brasil há bastante tempo. Na década de 60 do século passado, o governo militar, no afã de impulsionar um projeto de desenvolvimento nacional, definiu uma política de incentivos e isenções fiscais, com o propósito de apoiar vários setores da iniciativa privada, dentre os quais se incluía o da educação. O Código Tributário Nacional (BRASIL, 1966) estabelecia a não incidência de impostos sobre o patrimônio, a renda ou serviços de instituições de educação (Lei 5.172/1966, Art. 9º IV, c) (BRASIL, 1966 ). Nos anos 90, as instituições de ensino privadas passaram a ser classificadas em lucrativas e sem fins lucrativos, estas últimas subclassificadas em não beneficentes e filantrópicas. Após a promulgação da Lei de Diretrizes e Bases da Educação Nacional - LDBEN, em 1996 (BRASIL, 1996), as IES lucrativas deixaram de beneficiar-se diretamente de recursos públicos e, indiretamente, da renúncia fiscal, limitações que não atingiram as IES sem fins lucrativos, as quais permaneceram imunes à incidência tributária (CATANI; HEY; GILIOLI, 2006, p. 127). Nesse sentido, nova redação foi dada ao Art. $9^{\circ}$, IV, c, da Lei 5.172/1966 (BRASIL, 1966) pela Lei Complementar No 104, de 10 de janeiro de 2001, que restringiu o benefício tributário a instituições de educação sem fins lucrativos (BRASIL, 2001). A Lei n ${ }^{\circ} 11.096 / 2005$ prevê incentivo tributário para instituições privadas de ensino superior com ou sem fins lucrativos, o que foi motivo de questionamento, em especial no ponto de que trata o Art. $8^{\circ}$, que isenta a instituição aderente ao PROUNI dos seguintes tributos: Imposto de Renda das Pessoas Jurídicas, Contribuição Social sobre o Lucro Líquido, 
Contribuição Social para Financiamento da Seguridade Social e Contribuição para o Programa de Integração Social. Essa forma de financiamento foi objeto de artigo de Carvalho e Lopreato (2005), para quem o programa é mais favorável às instituições com fins de lucro, levando assim o PROUNI a ser caracterizado como uma parceria público-privada no setor educacional (LEHER, 2004).

A partir do financiamento pela via da renúncia fiscal, estava implantado o PROUNI, num momento em que a demanda reprimida por ensino superior atingia grandes proporções, sendo a universidade pública incapaz de absorver todo o universo de estudantes aptos a adentrar o mundo acadêmico. Boa parte do contingente que compunha essa demanda também não era capaz de arcar com ônus de um curso superior em uma instituição privada de ensino nem de ter acesso ao Programa de Financiamento Estudantil - FIES, dado o fato de o agente financiador exigir capacidade creditícia, procedimento comum nos empréstimos bancários.

O fato é que o PROUNI parece ter tido uma boa aprovação inicial por parte de sua potencial clientela. Em 2006, o número de inscrições para o PROUNI ultrapassou a casa dos $200 \mathrm{mil}$, tendo sido concedidas apenas pouco mais de 40 mil bolsas, o que representa somente $20 \%$ da demanda segundo dados do Boletim de Estudos Educacionais do INEP (Ano I, n. 3, 2009).

Com o PROUNI, o governo conseguiu também aumentar o índice de participação no ENEM (Exame Nacional do Ensino Médio), que saltou de um milhão, em 2004, para 2,9 milhões, no exame de 2008 de acordo com o Boletim de Estudos Educacionais do INEP (Ano I, n. 3, 2009). Esse crescimento pode ser relacionado à possibilidade de ingresso no ensino superior assegurada pelo programa, objetivo que prepondera entre os concluintes e egressos do ensino médio participantes do ENEM, tal como revelam os seguintes dados, também divulgados pelo MEC: depois da instituição do PROUNI, o número de concluintes do ensino médio que prestaram o ENEM tendo como motivação o objetivo de entrar no ensino superior saltou de 39 para 70\%. Além disso, merece destaque o fato de que a criação do PROUNI foi também responsável pelo aumento do percentual de participação no ENEM de pessoas com mais de 23 anos, em 2004, de 9,4\% e, em 2008, de 30,6\%, segundo o Boletim de Estudos Educacionais do INEP (Ano I, n. 3, 2009).

Em geral, as análises do PROUNI partem da premissa de que o programa se caracteriza como uma política pública de discriminação positiva, tida como fruto da imposição de organismos internacionais como o Banco Mundial e o Fundo Monetário Internacional - FMI, num momento em que o Brasil ainda estava sob a aura do neoliberalismo, doutrina que recomendava, e até exigia, 
a redução da máquina estatal, a qualquer preço (CARVALHO, 2008). Ainda sobre a gênese do PROUNI, várias são as críticas negativas apoiadas no fato de que sua criação revestiu-se de um caráter de conveniência, porquanto, a partir dos anos 90, paralelamente à situação de sucateamento que assolava as instituições federais de ensino superior (IFES), as IES privadas encontravam-se na iminência da inviabilidade financeira, dada a redução drástica da sua clientela, determinada pelas restrições econômicas vivenciadas à época no Brasil. Segundo Carvalho (2008), naquele momento, quando o ensino superior privado contabilizava um percentual de 37\% de vagas ociosas, as pressões das associações representativas do setor eram cada vez mais ostensivas, não havendo, pois, outra saída para o governo senão criar uma política educacional que representasse, além de um oportuno socorro às IES particulares, uma forma de silenciar, ainda que temporariamente, a grita da sociedade, principalmente dos seus segmentos médios, pela ampliação do acesso à educação superior (CARVALHO; LOPREATO, 2005). Carvalho (2006) analisa o PROUNI e opina que o programa não é capaz de resolver o problema da democratização do ensino superior, considerando que essa questão só pode ser equacionada com a efetiva expansão das IES públicas. Com relação a isso, cabe chamar a atenção para os números animadores referentes à expansão das IES públicas no Brasil que alcançou o percentual de 35,5\% no período 2001-2006 (SEGENREICH; CASTANHEIRA, 2009).

Um dado que alimenta vigorosamente as críticas negativas ao PROUNI remonta à reforma universitária de 1968, mais precisamente ao ponto em que o impedimento legal da dissociação do ensino, da pesquisa e da extensão restringiu-se tão só às instituições federais de ensino superior (IFES). Em outras palavras, a mencionada reforma, que pôs na pauta da educação superior palavras como flexibilização, diversificação e privatização, passou a ser vista como a outorga de prerrogativas demasiado amplas às instituições privadas, que tiveram alargado o seu campo de atuação. Na visão de Jimenez e Rocha (2007), quando se autorizou a oferta da educação superior pela iniciativa privada somente pela vertente do ensino, estava também sendo determinado o afrouxamento dos "últimos elos de salvaguarda da educação contra os arbítrios do mercado".

A criação do PROUNI parece ter estimulado proliferação de IES privadas, sendo esse o ponto para o qual converge o maior número das críticas negativas ao programa e o que mais serve de respaldo à acusação de que os empresários da educação são os seus reais beneficiários (LEHER, 2004; CARVALHO; LOPREATO, 2005; CATANI; HEY; GILIOLI, 2006). Na verdade, o crescimento do número de IES privadas já é observado desde antes do PROUNI, tendo alcan- 
çado 69,9\% no período 1996-2001 e 67,4\%, de 2001 a 2006 (SEGENREICH; CASTANHEIRA, 2009). O fato de $70 \%$ das IES privadas terem aderido ao PROUNI, tal como documentado por Andrade (2007), pode ser visto como um indicativo das vantagens para o setor. Segundo dados do Boletim de Estudos Educacionais do INEP (Ano 3, n. 7, 2011), o número de ingressantes em cursos superiores de graduação na rede privada foi de 1.856.015 estudantes, enquanto o setor público, aqui entendido como as IES das três esferas administrativas (federal, estadual e municipal), matriculou 490.680 novos alunos.

Além do que já foi aduzido, o fato de a Lei no 9.394, de 20 de dezembro de 1996 (BRASIL, 1996 ), que traçou as Diretrizes e Bases da Educação Nacional (LDB), e de o Plano Nacional de Educação (PNE), criado pela Lei $n^{\circ}$ 10.172, de 09 de janeiro de 2001 (BRASIL, 2001), terem preconizado a oferta de educação superior pela iniciativa privada, recrudesce a mordacidade das críticas ao PROUNI, tido como a materialização do enquadramento do sistema educacional brasileiro às regras de mercado. Afinado com essa ideia, Sguissardi (2008) defende que o governo brasileiro foi gradativamente legitimando "o ensino superior como uma mercadoria negociável no mercado de trocas e a universidade como genuína empresa econômica".

Pacheco e Ristoff (2004), analisando criticamente o projeto de lei que instituía o PROUNI, defenderam que os efeitos positivos dessa política estariam basicamente na dependência de um esforço combinado do governo, da academia e da sociedade. Isso porque, ao primeiro, impor-se-ia um elevado investimento financeiro, dada a renúncia fiscal que o programa implica; ao segundo, a grandeza de "repensar suas atitudes muitas vezes elitistas e excludentes" e ao terceiro, o reconhecimento de que "a perda de cérebros é altamente condenável e socialmente inaceitável para uma nação que se queira soberana”.

Catani, Hey e Gilioli (2006, p. 137-138), além de terem dito que o PROUNI, conquanto alargasse o acesso à educação superior, "não oferecia mais que um arremedo de cidadania de segunda classe aos contemplados", ainda questionaram o fato de o MEC não tornar públicos dados atinentes ao programa, tais como "total de bolsas contratadas, modalidades das bolsas concedidas (integrais e parciais), detalhamento dos cursos 'disponíveis' ou 'escolhidos', perfil dos alunos, taxas de evasão e desempenho escolar dos beneficiários". De fato, a expansão do acesso ao ensino superior é uma realidade inegável, tal como confirmam Neves, Raizer e Fachinetto (2007), conquanto, para eles, esse processo de democratização tenha um efeito perverso, pelo fato estar sendo operacionalizado por meio do sistema privado de educação superior, com financiamento público. 
Também analisando o PROUNI, Corbucci (2004) anima-se com a perspectiva de o programa materializar indiscutivelmente uma redistribuição indireta de renda, embora também afirme, num tom de crítica, que, ao transferir recursos de isenção fiscal a estratos populacionais mais pobres, o governo está, pelo menos, garantindo que esses mesmos recursos "não sejam desviados para outros fins menos nobilitantes", como sói acontecer. Na mesma direção, Santos (2012) encontra resultados que indicam a efetividade do PROUNI como instrumento de inclusão de grupos sociais historicamente excluídos da universidade, apesar de alertar para a necessidade de mecanismos de prevenção da evasão. Abordando a questão da evasão, estudo recente de Silva (2013) indica a bolsa do PROUNI como um fator que contribui para a propensão do aluno a concluir o curso.

Para rebater opiniões contrárias ao PROUNI, operadores do governo reagem com argumentos meramente opinativos, por exemplo, o de que "as críticas ao PROUNI são conservadoras (à direita ou à esquerda) e estão limitadas tão somente à crítica pela crítica, sem que outra saída seja apresentada" (LÁZARO, 2008).

$\mathrm{Na}$ verdade, o fato de os órgãos governamentais até agora não terem disponibilizado dados completos do PROUNI abre espaço para que formulações meramente teóricas a seu respeito continuem existindo.

\section{Metodologia e amostra}

\subsection{Metodologia}

Tendo em vista a natureza desta pesquisa, classificada como de levantamento, porquanto buscou obter, junto a um grupo relevante de pessoas, informações acerca do problema estudado (DALBERIO; DALBERIO, 2009), definiu-se como primeiro passo metodológico a construção de um instrumento de coleta de dados, mais precisamente um questionário, composto de quatro questões abertas: a) Por que você escolheu a formação acadêmica em curso? b) Você está enfrentando dificuldades para levar a termo sua formação superior (Se sua resposta foi sim, dê detalhes dessas dificuldades)? c) Como beneficiário do PROUNI, você se sente discriminado no ambiente universitário? d) Como você avalia o PROUNI?

Às respostas de cada estudante, aplicou-se um tratamento interpretativo-descritivo, perscrutando nelas aspectos implícitos e explícitos da linguagem, tomando por base a análise do discurso (ROCHA; DEUSDARÁ, 2005; ORLANDI, 2012).

Analisar o sentido de um texto pressupõe ultrapassar os limites da lógica, convindo, pois, considerá-lo não só como um enunciado, sujeito como tal às 
formalidades da morfossintaxe, mas sim, e principalmente, como uma enunciação, que carrega intenções, emoções e ideologia do seu produtor. Segundo Koch (1996, p. 25), é exatamente no espaço entre o enunciado e a enunciação que as relações discursivas e argumentativas se constroem, tendo, de um lado, um eu disposto a expressar-se e a interagir, e, do outro, um interlocutor igualmente constituído de um eu, ambos sujeitos a obrigações discursivas, resumidas no atendimento à lógica própria da linguagem, ou seja, no dever que tem cada um de dar sentido ao seu discurso, sob a pena de não conseguir fazê-lo avançar.

\subsection{Amostra}

O corpus desta pesquisa compõe-se de textos construídos em resposta às questões formuladas, os quais foram submetidos a uma análise do sentido da argumentação, com vistas a extrair-lhes, além da informação propriamente dita, por vezes presente na estrutura superficial, as eventuais representações linguísticas portadoras de implícitos.

Os dados foram colhidos junto a 50 bolsistas do PROUNI, de quatro IES privadas de Fortaleza, localizadas em distintas zonas da cidade. Cabe mencionar a dificuldade de acesso aos estudantes, haja vista que as próprias IES, quase na totalidade, negaram-se a receber a pesquisadora, sob a alegação de que as perguntas do questionário tinham um caráter capcioso.

A amostra apresenta boa distribuição em termos de idade, uma vez que $82 \%$ dos entrevistados situam-se na faixa etária de 19 a 25 anos, sendo 42 anos a idade mais avançada. Da mesma forma, há boa estratificação no que tange ao aspecto gênero, $58 \%$ homens e $42 \%$ mulheres. Respeitante aos cursos frequentados, os participantes da pesquisa distribuem-se em diferentes áreas do conhecimento, mais precisamente nos cursos Gestão de Turismo, Ciências Contábeis, Gestão Financeira, Secretariado, Design de Moda, Logística, Marketing, Pedagogia, Processos Gerenciais, Recursos Humanos, Redes de Computação, Administração e Engenharia de Produção.

\section{Análise do sentido e da argumentação}

A análise da fala dos beneficiários do PROUNI entrevistados tomou como base a seleção lexical predominante nas respostas e os marcadores de pressupostos (verbos, advérbios, palavras e locuções denotativas), levando em consideração tanto os elementos materializados na superfície textual quanto os nela implícitos. Assim, encarando a linguagem como portadora de sentidos claros e subentendidos e observando as posições dos sujeitos pesquisados, foi 
possível chegar mais perto do real desses sentidos. Em outras palavras, a partir das ideias literalmente expressas (explícitas), alcançaram-se outras igualmente importantes do ponto de vista da construção do sentido (implícitas). Cabe aqui registrar ter sido essa análise desenvolvida com a consciência de que, não sendo essencialmente objetiva, deveria ser o menos subjetiva possível. Além disso, esteve sempre presente a ideia de que nenhuma análise de argumentação tem caráter peremptório, haja vista que um mesmo discurso, dependendo do recorte que se lhe faça, comporta mais de uma interpretação.

Assim, para assegurar um caráter didático à análise, optou-se por vincular o respondente ao número atribuído a cada instrumento de coleta, procedimento efetuado depois de sua aplicação. Assim, ao se empregar, por exemplo, o símbolo $\mathrm{R} 1$, está-se fazendo alusão ao respondente de número um. As respostas foram separadas em blocos representativos de cada tema, o que se deu pelo critério da intertextualidade, que se caracteriza basicamente como a "superposição de um texto a outro" (FERREIRA, 2009). Reitere-se que as quatro questões propostas passaram por análise do conteúdo das mensagens, de modo a extrair dos enunciados, além dos sentidos postos na superficialidade linguística, outros tantos, implícitos nos operadores argumentativos empregados na construção dos argumentos.

\subsection{Opinião sobre a escolha do curso}

A pergunta do questionário respeitante à razão da escolha do curso teve o propósito averiguar se os estudantes escolheram livremente a formação acadêmica a ser cursada ou se, ao contrário, foram, de certa forma, obrigados a aceitar as opções disponibilizadas pela IES. Dessa forma, solicitou-se que o respondente indicasse a razão pela qual houvera escolhido a formação que está cursando. Dois deles (4\%) disseram não saber responder; os demais, totalizando 96\%, dividiram-se em respostas (selecionadas e transcritas na íntegra, depois de passarem por alguns ajustes linguísticos) construídas no entorno semântico dos seguintes temas: (i) Boa perspectiva de emprego; (ii) Aptidão; (iii) Limitações impostas pela IES.

(i) Respostas associadas a "Boa perspectiva de emprego" (36\% dos respondentes):

a) "Por achar mais fácil encontrar emprego". (R34)

b) "Por todo mundo dizer que é bom". (R12) 
c) "Por ser um curso promissor”. (R21)

d) "Por ser uma área nova, talvez eu arranje emprego". (R46)

e) "Por que eu acho que tem trabalho". (R50)

f) "Está precisando de profissional dessa área”. (R4)

g) “Já trabalho na área, pelo menos não vou ficar desempregado”. (R43)

À materialidade linguística deste primeiro grupo de respostas, subjazem relações de sentido, desenhadas pela ideologia na forma de interdiscurso, ou seja, ao afirmar que escolheu livremente a formação acadêmica ora em curso, o estudante estava capitulando aos apelos do mercado de trabalho, o que serve para reforçar a premissa de que o discurso é um produto linguístico e histórico-social a um só tempo (ORLANDI, 2012, p. 52). A análise da argumentação empregada pelos entrevistados, focada nos sentidos refletidos no texto, evidencia alguns pontos importantes a ser considerados. Na resposta do R34 ("Por achar mais fácil encontrar emprego"), o advérbio de intensidade mais, apesar de intensificar o sentido do adjetivo fácil, porta o implícito de que o aluno reconhece a dificuldade de entrar no mercado de trabalho, ou seja, ao dizer que "é mais fácil", o que lhe serve de referente semântico é o suposto menor grau de dificuldade que eventualmente terá que enfrentar para entrar no mercado de trabalho. No texto do R46 ("Por ser uma área nova, talvez eu arranje emprego"), o advérbio talvez desvitaliza a asserção, no caso, a suposta facilidade de arranjar emprego por estar se formando numa área nova. Já na resposta do R50 ("Por que eu acho que tem trabalho"), o verbo achar descredencia a opinião, isto é, ao tomar para si a responsabilidade da asserção, o estudante está revelando fraca convicção de que seja realmente certa a sua colocação no mercado de trabalho. Na resposta do R12 ("Por todo mundo dizer que é bom"), a expressão todo mundo carrega o implícito de que o respondente está reiterando, por meio da interdiscursividade, o caráter utilitário da formação acadêmica e, ao mesmo tempo, reduzindo a sua responsabilidade pela escolha do curso que faz. Melhor explicando, o produtor do discurso se exime de ser o único responsável por eventual insucesso profissional. Na superfície linguística da resposta do R4 ("Está precisando de profissional dessa área"), tem-se uma informação imprecisa, resultante do cruzamento semântico dos verbos precisar e faltar, o que pode ser indício de que a asserção não se reveste de certeza. $O$ R43, ao argumentar que o curso lhe dará a chance de emprego, usa a expressão "pelo menos", abrindo espaço para a redução de sua expectativa. Explicando 
melhor, a mencionada expressão pelo menos tem o papel discursivo de marcar uma condição favorável e mínima ao mesmo tempo, o que significa dizer estar o respondente inseguro quanto ao seu futuro profissional.

(ii) Respostas associadas à "aptidão" (22\% dos respondentes):

a) "Gosto de trabalhar com número desde pequeno". (R1)

b) "Porque me identifiquei com o curso técnico que fiz na área". (R16)

c) "É uma área que aprecio". (R17)

d) "Estou fazendo esse curso porque gosto de lidar com pessoas". (R2)

e) "Por ser uma área que me identifico muito". (R37)

Outros 11 alunos pesquisados $(22 \%)$ disseram ter escolhido a formação acadêmica em curso pelo critério da aptidão. Na verdade, nos textos analisados, encontram-se pistas discursivas que confirmam isso. Nas respostas do R1 e do R2 ("Gosto de trabalhar com número desde pequeno"; "Estou fazendo esse curso por que gosto de lidar com pessoas"), a presença do verbo gostar, flexionado no presente do indicativo, torna a afirmação categórica, isto é, passa ao destinatário da mensagem a convicção do seu emissor, pelo menos naquele momento. Em ambos os casos, ao mencionarem o objeto do prazer, os respondentes reiteram ter sido facultada a eles a escolha da formação em andamento. O R17, por sua vez, usa o verbo apreciar também de forma categórica, embora se possa sentir na margem do seu dizer uma convicção mais fraca que a revelada pelos dois outros respondentes. Nos argumentos usados pelos R16 e R37 ("Porque me identifiquei com o curso técnico que fiz na área"; "Por ser uma área que me identifico muito"), o verbo identificar-se aparece primeiro num contexto histórico, indicando o amadurecimento do ato de asserção; no segundo texto, aparece modalizado pelo advérbio de intensidade muito, o que reitera a certeza do aluno quando fez a escolha da formação profissional. Vista pelo sentido do não dito, as duas argumentações revelam que os alunos assumem a responsabilidade pela escolha da formação acadêmica em curso.

(iii) Respostas associadas a "limitações impostas pela IES" (38\% dos respondentes)

a) "Minha nota só dava pra esse". (R44)

b) "Foi o que deu pra fazer". (R31) 
c) "Só existiam duas opções e eu escolhi secretariado". (R32)

d) "Foi o que a bolsa do prouni permitiu". (R8)

e) "Por causa da nota de corte". (R19)

f) "Queria fazer pedagogia, mas minha nota não dava". (R15)

g) "Tive que fazer esse". (R47)

h) "Eu não escolhi. Tive que fazer gestão de pessoas". (R30)

Ao contrário dos dois primeiros grupos de respondentes, 19 alunos (38\%) revelaram insatisfação com o curso em andamento, tal como se pode observar no discurso dos textos transcritos. Nas respostas do R44 ("Minha nota só dava pra esse"), do R31 ("Foi o que deu pra fazer") e do R47 ("Tive que fazer esse"), fica subentendida a existência de certa limitação imposta aos alunos pela instituição quando da escolha da formação acadêmica. Outros, demonstrando um grau de entendimento mais elevado, atribuem ao PROUNI a responsabilidade pela restrição a eles imposta (Veja-se a resposta do R8: "Foi o que a bolsa do prouni permitiu"). Dois outros respondentes, o R32 ("Só existiam duas opções e eu escolhi secretariado") e o R30 ("Eu não escolhi tive que fazer gestão de pessoas"), deixaram mais clara a insatisfação com a formação em curso e o reconhecimento de restrições na escolha do curso, quando afirmaram ter sido sua escolha baseada no critério da exclusão. Na resposta do R15 ("Queria fazer pedagogia, mas minha nota não dava"), o emprego do verbo querer, flexionado no imperfeito do indicativo, denota frustração, porquanto, quando da escolha do curso, fato agora passado, a formação pretendida não lhe foi facultada. Em outras palavras, a forma verbal queria, embora seja pretérita, está desprovida do caráter de temporalidade, não significando, pois, nem "antes" nem "depois". Desse modo, a insatisfação do respondente não está inscrita no momento da escolha do curso como algo definitivamente passado, mas sim, como um fato que tem continuidade no presente.

A análise das respostas à primeira questão aberta do instrumento de coleta de dados desta pesquisa autoriza a ilação de que as imposições do mercado de trabalho e as conveniências das IES são fatores que parecem influenciar fortemente a escolha da formação acadêmica desses estudantes, muito mais que a aspiração e a aptidão pessoais. Melhor explicando, na maioria dos fragmentos discursivos mencionados, o pensamento límpido do sujeito não passa de um reflexo da realidade, tal como teoriza (ORLANDI, 2012), para quem, nas sociedades ditas democráticas, o sujeito "é ao mesmo tempo livre e submisso". 


\subsection{Opinião sobre as dificuldades no percurso formativo}

Indagou-se sobre eventuais dificuldades enfrentadas pelos beneficiários do PROUNI no curso da formação acadêmica, com o propósito de avaliar se esse coletivo de alunos depara com obstáculos à sua formação e se estes poderiam estar associados ao programa no qual estão inseridos. Dentre os entrevistados, 22 respondentes (44\%) disseram não estar enfrentando nenhuma dificuldade, enquanto outros $28(56 \%)$ responderam que essas dificuldades existem. Tal como se procedeu no bloco anterior, as respostas obtidas foram agrupadas por tema, definido pelo conteúdo discursivo extraído dos textos, e selecionados para a transcrição pelo critério da intertextualidade, cabendo aqui registrar que a maioria dos respondentes aduziu mais de uma justificativa a sua resposta. Para efeito de análise, os textos construídos pelos respondentes foram agrupados com base em três entornos semânticos: (i) Falta de tempo para estudo; (ii) Limitações econômicas; (iii) Falta de base.

(i) Respostas associadas à "falta de tempo para estudo" (36\% dos respondentes)

a) "Não tenho tempo de estudar". (R23)

b) "Nunca entrego os trabalho no dia pois não tenho tempo de fazer". (R29)

c) "Como não tenho tempo de estudar, tiro nota baixa". (R35)

d) "Não tenho como fazer os trabalhos, trabalho o dia todo". (R1)

e) "Todo dia saio tarde do trabalho e muitas vezes não vou". (R48)

f) "Trabalho muito longe e nunca consigo sair cedo". (R 22)

g) "Trabalho de motorista e não tenho hora pra largar". (R40)

h) "Meu trabalho é na padaria e a hora de mais movimento é a noite". (R30)

i) "O sindiônibus é muito longe e todo dia chego atrasado". (R32)

j) "Falto muito pois largo o trabalho de sete horas". (R33)

k) "Os trabalhos de casa tomam meu tempo". (R36)

Um contingente de $36 \%$ dos respondentes apontou fatores associados ao pouco tempo para o estudo como a dificuldade mais relevante no seu processo formativo. Nos trechos transcritos dessas respostas, resta explícito que a falta de tempo a que fazem alusão está intimamente ligada à atividade labo- 
ral que desenvolvem. Das respostas do R23, do R29 e do R35 ("Não tenho tempo de estudar"; "Nunca entrego os trabalho no dia pois não tenho tempo de fazer"; "Como não tenho tempo de estudar, tiro nota baixa”), depreende-se a intenção dos alunos de justificar o baixo desempenho acadêmico e até uma aceitação tácita dessa situação. Quando da ocasião da coleta de dados, indagando-se informalmente de alguns respondentes se o fato de eles não estarem fazendo um curso bem feito os preocupava, foram obtidas respostas do tipo "Se a gente for esperar ter tempo nunca vamos ter curso superior". No texto produzido pelo R48 (“...muitas vezes não vou”), pode-se observar que a responsabilidade de faltar à aula, fato referido como costumeiro, é assumida por ele com passividade, ou seja, não se nota na mensagem a compreensão de que o choque da atividade laboral com a formação acadêmica está contribuindo para enfraquecer o seu desejo de se promover socialmente, condição que pressupõe necessariamente uma formação profissional em níveis razoáveis de qualidade. Nos fragmentos discursivos do R48 e do R40 ("Todo dia saio tarde do trabalho e muitas vezes não vou"; "Trabalho de motorista e não tenho hora pra largar") a conjunção e, habitualmente empregada para indicar acrescentamento, está substituindo um operador indicativo de consequência, o que anuncia o pressuposto de ser mais conveniente aos pesquisados simplesmente indicar uma prática laboral estendida que cogitar a abusiva carga horária a que são submetidos.

(ii) Respostas associadas a "limitações econômicas" (12\% dos respondentes)

a) "Não tenho como ter um computador para me ajudar". (R48)

b) "Falta dinheiro". (R11)

c) "Tenho dificuldade financeira". (R5)

d) "Falta dinheiro para o ônibus". (R22)

e) "Não posso xerocar material e comprar livro". (R23)

f) “O dinheiro é pouco”. (R19)

Um número mais reduzido de respondentes (12\%) destacou a limitação econômica como dificuldade encontrada. $\mathrm{O}$ conteúdo discursivo das respostas selecionadas revela clara restrição financeira para fazer frente a eventuais despesas que o processo de formação acadêmica implica. É de se esperar a incidência dessa dificuldade uma vez que é 
exatamente a baixa renda familiar um dos critérios de concessão de uma bolsa PROUNI. No texto do R22 ("Falta dinheiro para o ônibus"), resta implícito o extremo da situação de dificuldade econômica vivida pelo estudante, o que, na sua visão, é um impeditivo ao seu bom desempenho. Mensagem semelhante esconde-se no laconismo das respostas do R11 e do R19 ("Falta dinheiro" e "O dinheiro é pouco") Ao construírem os respectivos textos, os respondentes revelam algo que não está dito na estrutura superficial: a baixa renda os está distanciando de uma formação satisfatória.

(iii) Respostas associadas à "falta de base" (8\% dos respondentes)

a) "Não acompanho todas as matéria". (R26)

b) "Dificuldade na matéria de física. Na escola que estudei o ensino era fraco demais". (R 24)

c) "Dificuldade com disciplina de cálculo". (R45)

d) "Não sei escrever nem gosto de fazer trabalho, só de grupo". (R39)

Um ínfimo grupo de estudantes ( $8 \%$ dos respondentes) encaminhou a análise para a argumentação de que o ensino básico ministrado nas escolas brasileiras merece reparos. Ao afirmar "Não sei escrever nem gosto de fazer trabalho, só de grupo", o R39, de forma categórica, revela sua vulnerabilidade intelectual, tal como o faz o R24 ("Dificuldade na matéria de física. $\mathrm{Na}$ escola que estudei o ensino era fraco demais"), nesse caso, transferindo à escola onde fez o ensino básico toda a responsabilidade por isso.

Cabe aqui ressaltar que o percentual de $56 \%$ dos alunos em dificuldade para dar seguimento à formação em curso, conquanto seja expressivo, não é alarmante. Ainda assim, resta subentendido a dificuldade que os beneficiários do PROUNI terão que enfrentar para vencer a defasagem intelectual com que adentram o ensino superior, sobretudo porque as limitações econômicas que a determinaram continuam a existir. O teor discursivo das respostas analisadas revela que um elevado número de beneficiários reconhece ter baixo desempenho acadêmico, sem, no entanto, fazer nenhuma cogitação acerca do que isso pode representar no seu futuro. 


\subsection{Opinião sobre a possível existência de discriminação}

Para se averiguar a ocorrência de casos de discriminação e de dificuldades de interação com alunos pagantes, formulou-se aos beneficiários do PROUNI pesquisados uma pergunta direta, com apenas duas opções de resposta, sim ou não. Um grupo de 35 beneficiários (70\%) negou a ocorrência de qualquer evento de discriminação no ambiente universitário. Outros 15 respondentes (30\%) assinalaram a opção sim e, conforme solicitado, complementaram a resposta com alguns comentários, transcritos e analisados adiante. Nesse caso em especial, as respostas foram agrupadas conforme o agente da discriminação apontado pelo estudante.

(i) Professores e funcionários (22\% dos respondentes)

a) "Os professores falam que a gente não tem base". (R48)

b) "Os professores reclamam pela falta de material". (R47)

c) "Só porque não tenho tempo de fazer os trabalhos os professores falam". (R15)

d) "Tudo que é de graça as pessoas passam na cara". (R19)

e) "Não os colegas, só os professores". (R14)

f) "Os professores dizem que a gente tem dificuldade de aprender". (R31)

g) "Todo mundo diz que nós somos fracos". (R5)

O primeiro bloco de comentários revela a insatisfação de 11 alunos (22\%) com a crítica ao seu desempenho acadêmico, no caso, feita pelos docentes. Nos comentários do R48, R31 e R5, os trechos "a gente não tem base"; "a gente tem dificuldade de aprender" e "nós somos fracos" carregam o implícito de que esses alunos, conquanto se reconheçam em situação de vulnerabilidade intelectual, repudiam a postura dos mestres, de quem, por certo, esperariam uma atitude contrária. Observe-se também que, ao empregar a expressão a gente e o pronome nós como sujeitos, os produtores dos textos agem como se desejassem ratear o efeito da acusação e assim serem menos atingidos por ela. Nos depoimentos do R47 e R19, mais uma vez está presente a situação econômica como fator de exclusão, o que se revela com mais contundência na declaração "Tudo que é de graça as pessoas passam na cara". Dois implícitos 
pressupostos essa afirmação esconde, quais sejam: o PROUNI é mais uma ação governamental de natureza caritativa e/ou benemérita; o código social oculto na superfície linguística leva o respondente a considerar-se, por ser pobre, um "meio" cidadão, com meios direitos, por isso, merecedor de benefícios e não credor de direitos. Em outras palavras, trata-se de um caso de naturalização do fenômeno da exclusão e de aceitação tácita da situação, como se nada houvesse a ser feito para revertê-la. Na verdade, a ideia implícita no texto de que o PROUNI materializa uma ação assistencialista esconde outra igualmente relevante para a análise dos argumentos, qual seja a de que o aluno pesquisado ainda não desenvolveu uma consciência crítica, tampouco assimilou a noção de igualdade de direitos, porquanto insinua no seu discurso estar sendo beneficiado pelo espírito altruísta de agentes do governo, dos quais se sente absolutamente descolado, politicamente falando. Melhor explicando, ao empregar a expressão de graça, o aluno se reconhece na posição de alguém que, por estar recebendo o ensino superior gratuitamente, deve ser socialmente cobrado por isso.

(ii) Colegas pagantes ( $8 \%$ dos respondentes)

a) "Não gosto quando os colegas ficam dizendo que eu não acompanho a matéria”. (R32).

b) "A gente ouve piada dos colegas". (R30)

c) "Os colegas criticam a gente". (R44)

d) "Intitulado de pobrinhos pelos colegas". (R6)

Os comentários de 04 beneficiários (8\%) que colocam os colegas pagantes como agentes do comportamento discriminatório são marcados tanto pelo sentimento de menos valia quanto pela passividade. $\mathrm{O}$ sufixo inho acrescentado à significação lexical da palavra pobre (pobrinhos) tem valor essencialmente afetivo, ou seja, afastado completamente da ideia de tamanho, assume a de crítica negativa, deixando bem claro que o respondente identifica a divisão existente entre alunos pagantes e beneficiários do PROUNI.

A análise dos dois grupos de comentários orienta para a conclusão de que a incidência de discriminação aos beneficiários do PROUNI, ainda que não seja acentuada, não é desprezível.

Saraiva e Nunes (2011) ), também analisando a inserção de beneficiários do PROUNI na rede particular de educação superior, entrevistaram 11 bolsistas, 
com vistas a detectar a incidência de discriminação no processo de interação desses estudantes com alunos pagantes. Os resultados alcançados por eles discrepam dos obtidos por esta pesquisa, ou seja, para os dois pesquisadores, os eventuais problemas respeitantes à adaptação dos bolsistas na IES privada são de só menos importância e "normalmente observados em uma situação de mudança de ambiente".

Considerando que a presente pesquisa trabalhou com uma amostra bem maior que a do trabalho de Saraiva e Nunes (2011), é cabível cogitar que problemas de discriminação aos beneficiários do PROUNI existem, conquanto sua incidência não seja generalizada.

\subsection{Apreciação pessoal do PROUNI}

A última pergunta reveste-se de larga importância, porquanto buscou uma apreciação do PROUNI à luz dos próprios beneficiários, a quem certamente o programa mais interessa. Incitados a emitir opinião sobre o programa, $92 \%$ dos estudantes pesquisados construíram textos semelhantes do ponto de vista da seleção lexical e do teor discursivo, como se pode ver a seguir:

a) "Um dos melhores programas feito pelo governo federal, pois dá oportunidade de pessoas mais carentes frequentarem uma faculdade privada, já que as públicas têm vagas muito reduzidas”. (R7).

b) "Bom programa do Governo Federal, dando oportunidade aos alunos mais carentes". (R10).

c) "É uma oportunidade para aqueles que não conseguiram ingressar na rede pública, podendo se formar mesmo assim”. (R41)

d) "Fundamental para a inclusão de pessoas carentes no ensino superior". (R27).

e) "Prouni é uma oportunidade para estudantes que não conseguem passar em instituição pública terem uma graduação superior”. (R28)

f) "É um ótimo benefício do governo, pois os melhores alunos que não entraram na faculdade pública têm a oportunidade de se tornar, mesmo assim, os melhores profissionais do Brasil". (R36)

g) “É bom pois eu não ia passar na federal”. (R14)

Outros quatro alunos $(8 \%)$ pesquisados produziram textos com teor discursivo semelhante aos anteriores, com o acréscimo de algumas observações: 
a) "O prouni é bom mas precisa melhorar". (R12).

b) "É um ótimo programa mas precisa de uma melhor fiscalização". (R46).

c) "Deveria ser mais ampliado e ter mais informação. Muitos alunos não são informados”. (R43).

d) "O governo quer ajudar de qualquer jeito, mas era melhor a federal". (R14).

A maioria dos textos trazem fragmentos discursivos explícitos que revelam a aprovação quase absoluta do PROUNI. Para expressar o reconhecimento do programa como uma oportunidade que o governo dá a pessoas carentes (R7, R10, R27), as coincidências no campo do léxico foram muitas. Isso prova que um bom número dos beneficiários pesquisados vê na concessão de bolsa de estudos na rede privada a única forma de garantir a formação superior aos estudantes das camadas sociais menos favorecidas. Assumindo a impossibilidade de chegar à universidade por outra via, os beneficiários pesquisados revelam-se reconhecidos ao governo federal, restando no teor discursivo o implícito de que eles julgam essa ação como benemérita e não como algo a que fazem jus como cidadãos. Convém considerar ainda que, na superfície discursiva do R41, do R28 e do R36, resta o implícito pressuposto de que a baixa qualidade do ensino básico público justificou a criação do PROUNI (..’.aqueles que não conseguiram ingressar na rede pública, podendo se formar mesmo assim" (R41); ..’.para estudantes que não conseguem passar em instituição pública terem uma graduação superior" (R28); "pois os melhores alunos que não entraram na faculdade pública têm a oportunidade de se tornar mesmo assim os melhores profissionais do Brasil" (R36). Ao tempo em que consideram o PROUNI uma ação governamental justa e necessária, sobretudo porque se destina a alunos de baixa renda e oriundos da rede escolar pública, os respondentes questionam o fato de não estarem à altura de cursar o ensino superior numa instituição da mesma natureza, tal como expressou o R14 ("É bom pois eu não ia passar na federal"). A fala do R36, no ponto em que afirma estarem fora das universidades estatais até mesmo "os melhores alunos da escola pública", atesta que a fragilidade do ensino nessas escolas é do conhecimento de sua clientela. Entretanto, o mesmo entrevistado, ao confiar na possibilidade de os beneficiários do PROUNI "se tornar os melhores profissionais do Brasil", dá ao programa um crédito de integral confiança. Da superfície do fragmento discursivo construído pelo 
R12 (“O prouni é bom mas precisa melhorar"), depreende-se que o PROUNI já comporta ajustes, conquanto não haja pistas linguísticas acerca do ponto de fragilidade do programa observado pelo respondente. Já nas afirmações feitas pelo R46 e pelo R43 (“É um ótimo programa mas precisa de uma melhor fiscalização"; "Deveria ser mais ampliado e ter mais informação. Muitos alunos não são informados"), está implícita a identificação de pontos de fragilidade do programa, ligados basicamente à sua operacionalização. No texto "O governo quer ajudar de qualquer jeito, mas era melhor a federal” (R14), a expressão "de qualquer jeito" comunica que, na visão do respondente, o PROUNI foi uma saída encontrada pelo governo para dar resposta às pressões populares e solucionar o problema da dificuldade de acesso às IES públicas. $\mathrm{O}$ argumento seguinte, introduzido pelo operador discursivo mas ("mas era melhor a federal"), desvitaliza claramente a asserção anterior, ou seja, induz ao pressuposto de que o beneficiário respondente, conquanto analise positivamente o PROUNI, não vê essa política como ideal. Na estrutura profunda do texto, o beneficiário do PROUNI revela-se desprestigiado por não ter tido acesso a uma IES pública.

\section{Conclusão}

Ao fim deste trabalho de pesquisa, realizado com o propósito de analisar o Programa Universidade para Todos - PROUNI a partir da visão de seus beneficiários, foi possível constatar tratar-se de um tema deveras controverso, razão por que ainda estará na pauta de discussões políticas e acadêmicas, por muito tempo.

Decorridos já nove anos da criação do PROUNI, são ainda muitos os antagonismos em torno dele. De um lado, analistas que só conseguem enxergar o programa como uma capitulação aos ditames do capitalismo; de outro, os que entendem ser necessário e urgente que o Brasil insista em quitar a dívida contraída com os segmentos mais baixos da pirâmide social, aos quais, historicamente, negou-se o jus à educação, em especial a de nível superior. Dessa forma, o debate sobre o PROUNI, programa que poderia resultar em avanços no campo da educação superior, peca pela baixa proficuidade, ainda que os argumentos dos dois lados sejam plausíveis.

Relativamente à ênfase dada pelo governo à democratização do acesso ao ensino superior com a participação da iniciativa privada, cada vez mais, têm sido postas em suspeição as reais finalidades das políticas afirmativas focadas nesse propósito. A recalcitrância dos analistas em considerar essas ações, mais precisamente o PROUNI, como uma capitulação aos interesses capitalistas de 
formar mão de obra excedente e assim baratear os custos com trabalhadores de certa forma encontra respaldo na omissão do MEC que, até agora, decorridos já nove anos de implantação dessa política de concessão de bolsas na rede privada, não divulgou dados completos do programa, tais como cursos disponibilizados pelas IES aderentes ao programa, diplomação, evasão e tempo médio de permanência dos beneficiários na instituição, da entrada até a diplomação.

Tentando analisar o PROUNI com um olhar o menos fragmentário possível, este trabalho, que se baseou na visão de um grupo de estudantes beneficiários, chegou a algumas ilações, por exemplo, a de que os participantes do PROUNI consideram estar o programa cumprindo o seu papel como política afirmativa, embora se possa observar no teor discursivo dos textos analisados certa inclinação a considerar a concessão de bolsas na rede privada uma espécie de ação benemérita, praticada pelo governo federal para socorrer estudantes que não conseguem vaga na universidade pública. A análise dos textos evidenciou também a ocorrência de casos de discriminação enfrentados pelos beneficiários do programa, cabendo aqui registrar ter sido relativamente alto o percentual deles que apontou os professores como agentes dessa discriminação. Foi também possível captar nos textos analisados que um pequeno número de participantes do programa tem a compreensão de que o PROUNI já reclama ajustes, embora não tenham ficado claros, tampouco subentendidos, os pontos em que essas mudanças se fazem necessárias.

Certo é que insurgir-se contra esse programa sem avaliá-lo profundamente ou, pior ainda, condená-lo peremptoriamente, sob a alegação de que se trata tão só de uma transigência à lógica capitalista, é abonar o recrudescimento das desigualdades sociais, é negar o direito de todos à emancipação pela via do conhecimento. Cabe aqui, entretanto, uma ponderação: sendo o PROUNI uma política afirmativa, não se deve aceitar que assuma um caráter de ação permanente. Muito ao contrário, todos os fatores que deram motivo a sua criação, por exemplo, a distribuição injusta da renda e a baixa qualidade do ensino básico, devem ser igualmente enfrentados.

\section{Referências}

AMARAL, D. P.; OLIVEIRA, F. B. O Prouni e a conclusão do ensino superior: Novas trajetórias pessoais e profissionais dos egressos. Ensaio: Avaliação e Políticas Públicas em Educação, Rio de Janeiro, v. 19, n. 73, p. 861-890, 2011. 
ANDRADE, E. D. C. Effects of the Brazilian University Policy of Targeting the Poor. Estudos Econômicos, São Paulo, v. 37, n. 3, p. 663-683, 2007. BOLETIM DE ESTUDOS EDUCACIONAIS DO INEP. Brasília: INEP, Ano I, n. 3, 2009.

BOLETIM DE ESTUDOS EDUCACIONAIS DO INEP. Brasília, INEP, Ano 3, n. 7, 2011.

BRASIL. Lei n. 5.172, de 25 de outubro de 1966. Dispõe sobre o Sistema Tributário Nacional e institui normas gerais de direito tributário aplicáveis à União, Estados e Municípios. (Código Tributário Nacional). Brasília: Congresso Nacional, 1966.

BRASIL. Lei Complementar n. 104, de 10 de janeiro de 2001. Altera dispositivos da Lei no 5.172, de 25 de outubro de 1966 - Código Tributário Nacional. Brasília: Congresso Nacional, 2001.

BRASIL. Lei n. 8.436, de 25 de junho de 1992. Institucionaliza o Programa de Crédito Educativo para Estudandes Carentes. Brasília: Congresso Nacional, 1992.

BRASIL. Lei n. 9.288, de 1 de julho de 1996. Altera dispositivos da Lei $\mathbf{n}^{\circ}$ 8.436, de 25 de junho de 1992, que institucionaliza o Programa de Crédito Educativo para estudantes carentes. Brasília: Congresso Nacional, 1996.

BRASIL. Lei n. 9.394, de 20 de dezembro de 1996. Estabelece as diretrizes e bases da educação nacional. Brasília: Congresso Nacional, 1996.

BRASIL. Lei n. 10.172, de 9 de janeiro de 2001. Aprova o Plano Nacional de Educação e dá outras providências. Brasília: Congresso Nacional, 2001.

BRASIL. Lei n. 10.260, de 12 de julho de 2001. Dispõe sobre o Fundo de Financiamento ao estudante do Ensino Superior e dá outras providências. Brasília: Congresso Nacional, 2001.

BRASIL. Lei n. 11.096, de 13 de janeiro de 2005. Institui o Programa Universidade para Todos - PROUNI, regula a atuação de entidades beneficentes de assistência social no ensino superior; altera a Lei no 10.891, de 9 de julho de 2004, e dá outras providências. Brasília: Congresso Nacional, 2005. 
BRASIL. Lei n. 11.941, de 27 de maio de 2009. Altera a legislação tributária federal relativa ao parcelamento ordinário de débitos tributários. Brasília: Congresso Nacional, 2009.

CARVALHO, C. H. A. O PROUNI no governo Lula e o jogo político em torno do acesso ao ensino superior. Educação e Sociedade, Campinas, v. 27, n. 96, p. 979-1000, 2006.

CARVALHO, C. H. A. Política econômica, finanças públicas e as políticas para a educação superior: de FHC (1995 a 2002) a Lula (2003 a 2006). In: RODRIGUEZ, M. V.; ALMEIDA, M. D. L. P. D. (Ed.). Políticas educacionais e formação de professores em tempos de globalização. Brasília: Liber Livro, 2008.

CARVAlHO, C. H. A.; LOPREATO, F. L. C. Finanças Públicas, Renúncia Fiscal e o ProUni no Governo Lula. Impulso, Piracicaba, v. 16, n. 40, p. 93-104, 2005.

CATANI, A. M.; HEY, A. P. A educação superior no Brasil e as tendências das políticas de ampliação de acesso. Atos de Pesquisa em Educação, Blumenau, v. 2, n. 3, p. 414-429, 2007.

CATANI, A. M.; HEY, A. P.; GILIOLI, R. D. S. P. PROUNI: democratização do acesso às instituições de ensino superior? Revista Educar, Curitiba, v. 28, p. 125-140, 2006.

CORBUCCI, P. R. Financiamento e democratização do acesso à educação superior no Brasil: da deserção do Estado ao projeto de reforma. Educação \& Sociedade, Campinas, v. 25, n. 88, p. 677-702, 2004.

DALBERIO, O.; DALBERIO, M. C. B. Metodologia científica: desafios e caminhos. São Paulo: Paulus, 2009.

FÁVERO, M. D. L. D. A. A Universidade no Brasil: das origens à Reforma Universitária de 1968. Educar, Curitiba, v. 28, p. 17-36, 2006.

FERREIRA, A. B. H. Novo dicionário Aurélio da língua portuguesa. Curitiba: Positivo, 2009.

JIMENEZ, S. V.; ROCHA, A. R. M. Educação à venda: sucesso e cidadania na medida do seu bolso. In: JIMENEZ, S. V.; SILVA, M. F. A. (Ed.). 
Políticas públicas e reprodução do capital. Fortaleza: Edições UFC, 2007. p. $15-41$.

KOCH, I. G. V. Argumentação e linguagem. 4. ed. São Paulo: Cortez, 1996.

LÁZARO, A. Educação e desigualdade: o papel do PROUNI. Revista PROUNI, Brasília, v. 1, p. 26-29, 2008.

LEHER, R. Para silenciar os campi. Educação \& Sociedade, Campinas, v. 25, n. 88, p. 867-891, 2004.

NEVES, C. E. B.; RAIZER, L.; FACHINETTO, R. F. Acesso, expansão e eqüidade na educação superior: novos desafios para a política educacional brasileira. Sociologias, Porto Alegre, v. 17, p. 124-157, 2007.

ORLANDI, E. P. Discurso em análise: sujeito, sentido, ideologia. 2. ed. Campinas: Pontes, 2012.

PACHECO, E.; RISTOFF, D. I. Educação superior: democratizando o acesso. Avaliação, Campinas, v. 9, n. 4, p. 9-24, 2004.

ROCHA, D.; DEUSDARÁ, B. Análise de conteúdo e análise do discurso: aproximações e afastamentos na (re)construção de uma trajetória. Alea, Rio de Janeiro, v. 7, n. 2, p. 305-322, 2005.

SANTOS, C. T. Ações afirmativas no ensino superior: análise do perfil socioeconômico e da experiência universitária de bolsistas do ProUni na PUC-Rio. Revista Brasileira de Estudos Pedagógicos, Brasília, v. 93, n. 235, p. 770-790, 2012.

SARAIVA, L. A. S.; NUNES, A. D. S. A efetividade de programas sociais de acesso à educação superior: o caso do ProUni. Revista de Administração Pública, Rio de Janeiro, v. 45, n. 4, p. 941-964, 2011.

SEGENREICH, S. C. D. ProUni e UAB como estratégias de EAD na expansão do Ensino Superior. Pro-Posições, Campinas, v. 20, n. 2, p. $205-$ $222,2009$.

SEGENREICH, S. C. D.; CASTANHEIRA, A. M. Expansão, privatização e diferenciação da educação superior no Brasil pós - LDBEN/96: evidências e tendências. Ensaio: Avaliação e Políticas Públicas em Educação, Rio de Janeiro, v. 17, n. 62, p. 55-86, 2009. 
SGUISSARDI, V. Modelo de expansão da educação superior no Brasil: predomínio privado/mercantil e desafios para a regulação e formação universitária. Educação e Sociedade, Campinas, v. 29, n. 105, p. 991-1022, 2008.

SILVA, G. P. Análise de evasão no ensino superior: uma proposta de diagnóstico de seus determinantes. Avaliação, Campinas; Sorocaba, v. 18, n. 2, p. 311-333, 2013.

SILVA, M. D. G. M.; VELOSO, T. C. M. A. Acesso nas políticas da educação superior: dimensões e indicadores em questão. Avaliação, Campinas; Sorocaba, v. 18, n. 3, p. 727-747, 2013.

WORLD BANK. Higher education: the lessons of experience. New York: Oxford University Press, 1994.

ZANDAVALLI, C. B. Avaliação da educação superior no Brasil: os antecedentes históricos do SINAES. Avaliação, Campinas; Sorocaba, v. 14, n. 2, p. 267-290, 2009.

Tereza Lúcia Lima Fontele - Instituto Federal de Educação, Ciência e Tecnologia do Ceará | Fortaleza $|\mathrm{CE}|$ Brasil. Contato: tetelma9@gmail.com

Vicente Lima Crisóstomo - Universidade Federal do Ceará Fortaleza $|\mathrm{CE}|$ Brasil. Contato: vicentelc@gmail.com

Artigo recebido em 2 de abril de 2014 e aprovado em 5 de agosto de 2014. 
